Hartmut Sangmeister/Alexa Schönstedt

\title{
Tordesilhas revisado: perspectivas de novas alianças econômicas no espaço andino
}

\section{Um breve histórico}

O Tratado de Tordesilhas foi assinado, em 1494, entre Portugal e Castela para definir a partilha do Novo Mundo entre ambas as Coroas, um ano e meio após o navegador Cristóvão Colombo ter reclamado a América para Isabel a Católica.

O engajamento de Portugal na descoberta de novas vias marítimas para Índia e as costas da África tornou o país, no fim do século XV, à potência naval mais poderosa da Europa. Mas com as viagens de descobrimento do Colombo em serviço do Corte de Castela surgiu a necessidade de definir regras para partilhar as novas reivindicações territoriais entre as duas potências marítimas para evitar conflitos bélicos.

Uma primeira linha demarcatória tem sido decretada, já em 1493, na Bula Inter Coetera pelo pontífice Alexandre VI, espanhol de Valência e inclinado a favorecer os soberanos de Castela. A linha imaginária se estendeu do pólo norte ao pólo sul no Atlântico, aproximadamente 100 léguas a oeste das ilhas dos Açores e de Cabo Verde. Todos os direitos territoriais do chamado Novo Mundo ao oeste dessa linha foram adjudicados à Espanha. A posse de todos os territórios situados a leste da linha foi concedida a Portugal, ou seja, os territórios na África e na Ásia.

Devido ao fato de que Portugal se sentiu desfavorecido com essa partilha do mundo, a Coroa portuguesa não aceitou a adjudicação do papa. Um novo meridiano demarcatório foi fixado no Tratado de Tordesilhas, em junho de 1494. Em princípio, o Tratado de Tordesilhas resolveu os conflitos que seguiram a descoberta do Novo Mundo, garantindo a Portugal o domínio das águas do Atlântico Sul. Ratificado em 1506 pelo papa Júlio II, por petição do rei de Portugal D. Manuel I, o Tratado de Tordesilhas vigorou até 1750, quando foi revogado pelo Tratado de Madri. Mas o tratado teve vida útil limitada, pois desde cedo foi questionada a partilha do mundo entre as nações ibéri- 
cas e tratados, assinados com pompa e cerimônia, não saíram do papel. Como a nova linha se situou cerca de 370 léguas (cerca de 1.770 quilômetros) ao oeste de Cabo Verde, o Brasil foi incorporado no império português. No entanto, Portugal ignorou de fato a linha de demarcação acordada no Tratado de Tordesilhas. Portugueses e brasileiros não respeitaram o tratado e ocuparam as terras que seriam dos espanhóis, estendendo o território sob a jurisdição portuguesa cada vez mais, até chegar às fronteiras do Brasil contemporâneo. Já em 1750 foi concluído um novo acordo com a Espanha que revogou o Tratado de Tordesilhas. Mas foi apenas em 1779 que a Espanha e Portugal delimitaram definitivamente seus interesses na América Latina.

Conquistada a independência pelas nações latino-americanas, surgiu a idéia de que os povos da América Latina nunca serão felizes enquanto a diversidade da América Latina continua opondo-se à sua unidade. Ninguém outro personificou a idéia de uma América Latina unida tanto como Simón Bolívar (1783-1830), o herói da liberação do colonialismo espanhol. O Libertador, nascido no dia 24 de julho de 1783 em Caracas, Venezuela com o nome de Simón José Antonio de la Santísima Trinidad Bolívar y Palacios, foi um adepto das idéias políticas do filósofo francês Jean-Jacques Rousseau. Na idade de 16 anos, Bolívar visitou a Europa para continuar os seus estudos. Profundamente impressionado pelas transformações político-revolucionárias da época napoleônica na Europa, ele voltou, em 1807, para Venezuela.

O primeiro grande sucesso de Bolívar e seus companheiros de arma no caminho rumo à unificação tão pretendida de uma América Latina independente foi, em 1819, a fundação da República de GrãColômbia. Seu território chegou a compreender a área das atuais repúblicas de Venezuela, Colômbia, Equador e Panamá. Nomeado presidente da República de Grã-Colômbia, em 1821, Simón Bolívar convidou as autoridades dos novos Estados ibero-americanos, declarados independentes, a reunir-se para levar a cabo a sua visão da unidade política do subcontinente, criando uma confederação dos povos iberoamericanos, de México à Argentina e Chile. Mas o Congresso de Panamá, realizado de 22 de junho a 5 de julho de 1826, terminou sem nenhum resultado viável. $O$ governo da Argentina decidiu de não assistir. Embora Bolívar se tenha oposto à participação dos Estados 
Unidos de México, eles enviaram dois representantes, dos quais um morreu já no caminho e o outro só chegou quando o Congresso já havia finalizado. Brasil e Chile tampouco enviaram representantes. $\mathrm{O}$ Haiti, naquela época um dos poucos Estados independentes no Caribe, não foi invitado a participar. E finalmente, Simon Bolívar, o Libertador, que sonhou de uma grande Colômbia como única nação iberoamericana, teve de observar seu sonho se desmoronando. A República de Grã-Colômbia deixou de existir em 1830. Quando Bolívar morreu, no mesmo ano, estava desencantado e em bancarrota, asilado na casa de um espanhol.

É bem lembrar que os fracassos foram predominantes na quase bicentenária história das tentativas visando criar uma América Latina unida. A realidade da América Latina, dividida por fronteiras e interesses contrários, sempre se mostrou mais forte que a retórica integracionista regional. Um abismo profundo entre a retórica política e os contratos firmados por um lado, e o verdadeiro comportamento dos atores nacionais e sua interpretação dos acordos por outro lado, têm caracterizado por muito tempo os projetos de integração regional na América Latina. Ademais, existiam diferentes pontos de vista no que se refere à função de um processo regional de integração. Enquanto os representantes da "tese mercantilista" consideravam os acordos de integração como um instrumento para fomentar o comércio intraregional, os defensores da "tese desenvolvimentista" os viam como um instrumento para fomentar o desenvolvimento industrial de seus países. Face às distintas intenções e interpretações, aqueles convênios de cooperação estavam condenados a fracassar que não continham mais que um acordo baseado em um mínimo comum denominador de interesses contrários das partes contratantes.

Apesar das poucas experiências alentadoras do passado, ao final dos anos oitenta do século XX, projetos latino-americanos de integração tiveram novamente fortes impulsos. $\mathrm{O}$ ressurgimento de projetos regionais de integração foi, por um lado, uma reação dos países latinoamericanos à tendência global de formar blocos econômicos regionais, como o Tratado de Livre Comércio da América do Norte (TLCAN), a União Européia (UE) e a Associação de Nações do Sudeste Asiático (ASEAN). Se os países latino-americanos não queriam ver-se isolados frente a estas alianças, tiveram de escolher entre duas opções: ou tinham afiliar-se a um destes blocos ou desenvolver suas próprias formas 
de cooperação e formar, por sua vez, autênticos blocos regionais. A preocupação séria de ver-se à margem da economia mundial e a erosão progressiva da competitividade internacional levaram os países latino-americanos a cambiar os objetivos da sua política de integração e a revisar as suas estratégias de cooperação regional.

Mas de certo modo, o renascimento da "moda integracionista" foi também impulsionado pelo câmbio de paradigmas na política econômica. No marco da chamada "revolução neoliberal", a integração ofensiva no mercado mundial orientada às exportações tomou o lugar do modelo da substituição defensiva de importações, preferido na América Latina durante meio século. Viajar em comboio parecia aparentemente ser mais seguro no caminho difícil rumo ao mercado mundial.

Houve então uma verdadeira proliferação de novos projetos e acordos de integração regional na América Latina. E, como resultado, quase todos os países latino-americanos pertencem atualmente a uma ou a várias alianças (sub-)regionais de integração econômica, além de múltiplos acordos bilaterais. Faz parte dessa "terrina de espaguetes" a Comunidade Andina das Nações (CAN), cuja vida útil parece ser limitada, pois uma nova linha de Tordesilhas ameaça dividir o espaço andino. Essa vez a linha demarcatória não é imposta por poderes imperiais afora da região, mas sim, é resultado de diferenças políticoideológicas que separam a região.

\section{A Comunidade Andina das Nações: Cronologia de uma morte agônica}

A história da Comunidade Andina (inicialmente conhecida com o nome de Pacto Andino ou Grupo Andino) foi caracterizada por avanços modestos e retrocessos sérios - como ocorreu com qualquer outro projeto de integração na América Latina.

Foi no dia de 26 de maio de 1969 que os cinco países sulamericanos Bolívia, Chile, Colômbia, Equador e Peru tinham assinado o Acordo de Cartagena. Com esse acordo foi posto em marcha o processo andino de integração, com o propósito de melhorar, juntos, o nível de vida de seus habitantes mediante a integração regional e a cooperação econômica e social. O objetivo do acordo foi a promoção do desenvolvimento econômico e social na região andina através da 
formação de um mercado comum - mas só a longo prazo. Embora a Venezuela tenha participado nas negociações, o país assinou o acordo somente em 1973. O Chile, aonde o General Augusto Pinochet assumiu, em 1973, o poder através de um golpe de Estado, deixou o Pacto Andino em 1976. O presidente do Peru, Alberto Fujimori, suspendeu a participação do seu país no Pacto Andino em 1992, fato que deixou a economia exportadora do Peru reclamar a perda de um mercado de 200 milhões de dólares. Foi somente em 1997, que o Peru assumiu novamente os direitos e obrigações do Acordo de Cartagena, reingressando no bloco andino que, desde 1996, possui o nome programático Comunidade Andina das Nações (CAN).

Os países da CAN assumiram o compromisso de estabelecer, a mais tardar em 2005, um Mercado Comum, fase superior da integração que se caracteriza pela livre circulação de bens, serviços, capitais e pessoas. Com a sua formação se busca formar um solo mercado interior, que constitui um único território econômico, capaz de multiplicar as oportunidades comerciais, de investimento e emprego, para empresários e trabalhadores andinos e de terceiros países, e de garantir uma melhor inserção na economia mundial.

A circulação de mercadorias relativamente livre é uma realidade na CAN desde 1993, ano em que se terminara a eliminação das tarifas aduaneiras e de outros tipos de obstáculos ao comércio entre os países membros da CAN com a finalidade de constituir uma Zona de Livre Comércio. A liberalização do comércio de serviços, que se vem realizando em forma gradual e progressiva, registrava avances, particularmente nos setores de transportes e telecomunicações. Este processo consistiu na eliminação gradual das medidas que restringem o acesso ao mercado e o trato nacional. Para lograr a livre circulação de capitais se tem previsto - sem data fixa - eliminar as medidas que restringem o movimento do capital, harmonizar as normas de regulação bancária e financeira e adotar sistemas de cooperação entre as Bolsas de Valores dos países membros, entre outras medidas. A livre circulação de pessoas recebeu um significativo impulso em junho de 2001, com o reconhecimento dos documentos nacionais de identificação como único requisito para viajar — na qualidade de turista - entre as cinco nações da sub-região. Os primeiros esforços para a conquista desta liberdade foram realizados em 1977, quando se aprovaram os 
instrumentos andinos de Migração Laboral e de Segurança Social, que estão sendo adequados à situação atual.

Em 2006 se registraram acontecimentos que, sem dúvida, continuam impactar de qualquer modo o processo de integração andina. No mês de abril de 2006, a Venezuela decidiu retirar-se da CAN e no dia 20 de setembro do mesmo ano, o Conselho Andino de Ministros de Relações Exteriores outorgaram ao Chile a condição de País Membro Associado da CAN, abrindo assim o caminho para o reingresso do país.

Atualmente, a CAN agrupa quatro países com uma população total de cerca de 100 milhões de habitantes, uma superfície de 3,75 milhões de quilômetros quadrados e um Produto Interior Bruto (PIB) agregado de 338.371 milhões de US\$ em 2007. É, sem dúvida, uma sub-região sul-americana, com um perfil próprio. Mas o fato é que os quatro países que estão formando atualmente a CAN apresentam uma mistura heterogênea com respeito à população, ao poder econômico e ao nível de desenvolvimento humano (veja quadro 1 e 2).

Quadro 1: A população e o PIB dos países da CAN em 2007

População (milhões)

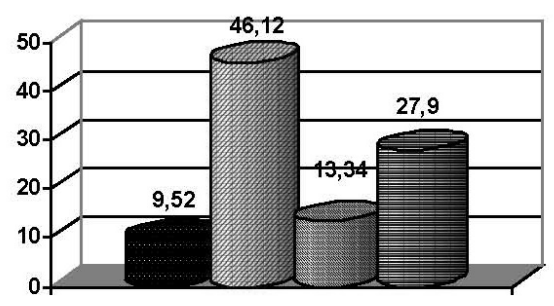

Bolívia 国 Colômbia
Produto Interno Bruto (milhões)

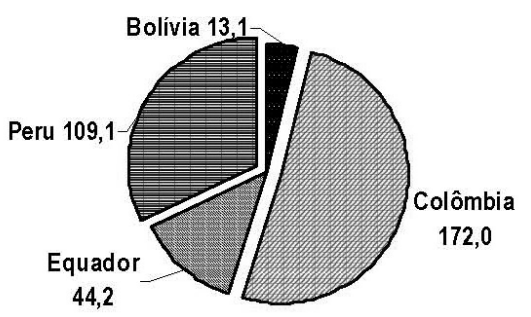

Fonte: World Bank, World Development Indicators Online.

Em termos econômicos, a CAN nunca foi mais que uma união aduaneira incompleta. A União Aduaneira Andina está funcionando desde 1995, ano em que entrou em vigor uma Alíquota Externa Comum, adotada por Colômbia, Equador e Venezuela - com muitas exceções. O Peru não subscreveu este acordo. A Bolívia tem um tratamento preferencial. Mesmo assim, esperava-se que a perspectiva de estabele- 
cer um Mercado Comum Andino como aperfeiçoamento do processo de integração atuará como catalisador para a convergência sub-regional. Mas, na realidade andina, os efeitos de divergência têm se mostrado mais vigorosos.

Quadro 2: O índice do desenvolvimento humano dos países da CAN em 2006

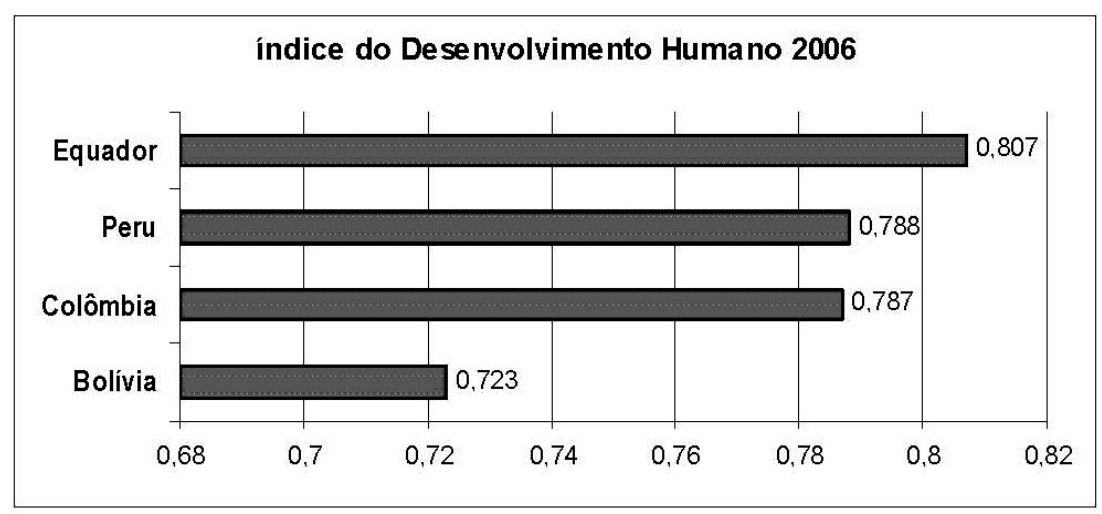

Fonte: UNDP Human development indices: A statistical update 2008. New York 2008.

Em seus cerca de 40 anos de existência, o processo andino de integração produziu alguns avanços administrativo-políticos, mas somente modestos efeitos comerciais e econômicos. Hoje em dia é possível para os cidadãos dos países-membros da CAN de atravessar as fronteiras para os vizinhos com o documento nacional de identidade, sem necessitar passaporte ou visto oficial. Existem normas comuns que garantem a circulação e a permanência de cidadãos andinos na sub-região para funções assalariadas, sem perder os direitos de previdência social do seu país de origem. Foram iniciados os primeiros passos para o voto popular e direto do Parlamento Andino. Existe um Plano Integrado de Desenvolvimento Social nas áreas de emprego, saúde e de educação, bem como uma Agenda Ambiental.

É bem lembrar que apesar de alguns efeitos positivos no campo político, de caráter mais ou menos simbólico, as relações do comércio intra-regional na CAN continuam a ser relativamente restritas. Em 2007 somente $8 \%$ do comércio exterior dos países da CAN foram 
destinados para os outros membros do bloco regional - ainda menos que uma década atrás (tabela 1 e 2).

Tabela 1: $O$ entrelaçamento do comércio exterior da CAN 1990-1999 a 2006*

\begin{tabular}{|c|c|c|c|c|c|c|c|c|c|c|}
\hline \multirow{3}{*}{$\begin{array}{r}\text { Região de } \\
\text { destino } \\
\text { Região de } \\
\text { origem }\end{array}$} & \multicolumn{10}{|c|}{ Exportações para outros blocos em \% das exportações totais da CAN } \\
\hline & \multicolumn{2}{|c|}{$\mathbf{C A N} \mathbf{N}^{6}$} & \multicolumn{2}{|c|}{$\mathrm{MCCA}^{\mathrm{C}}$} & \multicolumn{2}{|c|}{ MERCOSUL $^{\mathrm{d}}$} & \multicolumn{2}{|c|}{$\begin{array}{l}\text { América } \\
\text { Latina }\end{array}$} & \multicolumn{2}{|c|}{ TLCAN $^{\mathrm{e}}$} \\
\hline & $\begin{array}{l}1990 \\
199^{\mathrm{a}}\end{array}$ & 2006 & $\begin{array}{r}1990 \\
/ 99^{\mathrm{a}}\end{array}$ & 2006 & $\begin{array}{c}1990 \\
/ 99^{\mathrm{a}}\end{array}$ & 2006 & $\begin{array}{c}1990 \\
/ 99^{\mathrm{a}}\end{array}$ & 2006 & $\begin{array}{c}1990 \\
/ 99^{\mathrm{a}}\end{array}$ & 2006 \\
\hline CAN $^{\mathrm{b}}$ & 9,8 & 8 & 1,8 & 1 & 3,6 & 3 & 21,8 & 17 & 47,3 & 46 \\
\hline
\end{tabular}

* Estimativas preliminares. ${ }^{a}$ Valores médios do período 1990-99. ${ }^{\text {b }}$ Comunidade Andina das Nações: Bolívia, Colômbia, Equador, Peru, (Venezuela até 2006). ${ }^{\text {c }}$ Costa Rica, El Salvador, Guatemala, Honduras, Nicarágua. ${ }^{\mathrm{d}}$ Mercado Comum do Sul: Argentina, Brasil, Paraguai, Uruguai, (Venezuela a partir de 2007); sem dados para os países associados. ${ }^{\text {e }}$ Tratado de livre comércio da América do Norte: Canadá, México, Estados Unidos da América.

Fonte: Sangmeister/Fuentes (2002), p. 28; Inter-American Development Bank (2007). 
Tabela 2: Exportações intra-blocco dos países da CAN 2007 (US\$ milhões)

\begin{tabular}{|l|c|c|c|c|c|}
\hline Socio & Bolívia & Colômbia & Equador & Peru & Venezuela \\
\hline Bolívia & - & 154,5 & $19,0^{1}$ & $225,0^{1}$ & $242,1^{1}$ \\
\hline Colômbia & 65,6 & - & $1.276,0$ & 806,1 & $5.210,3$ \\
\hline Equador & $13,0^{\mathrm{a}}$ & $650,6^{\mathrm{a}}$ & - & $1.491,9^{\mathrm{a}}$ & $484,1^{\mathrm{a}}$ \\
\hline Peru & $223,9^{\mathrm{a}}$ & $616,6^{\mathrm{a}}$ & $379,1^{\mathrm{a}}$ & - & $765,3^{\mathrm{a}}$ \\
\hline Venezuela & $2,2^{\mathrm{a}}$ & $585,6^{\mathrm{a}}$ & $191,0^{\mathrm{a}}$ & $103,6^{\mathrm{a}}$ & - \\
\hline
\end{tabular}

$\mathrm{a}=2006$.

Fonte: UN Comtrade (2009).

Qual será o futuro da CAN? Não há dúvida nenhuma que a existência da CAN está severamente ameaçada. Alguns países membros da CAN entabularam negociações bilaterais sobre livre comércio com os EUA. Em conseqüência, várias normas e regras da CAN devem ser modificadas porque não são compatíveis com os acordos bilaterais que países membros fecharam com os EUA ou estão negociando com a União Européia. Conflitos latentes que se tornam reais podem significar o réquiem para a CAN (p. ex. conflitos entre Equador e Colômbia, entre Bolívia e Chile). Por enquanto é pouco provável que as economias andinas terão condições de tirar vantagens duráveis da globalização sem uma modificação das suas estruturas produtivas e sem um melhoramento significativo da sua competitividade internacional.

\section{Novos projetos e modelos de integração}

Os dois tradicionais blocos de integração na América do Sul, a CAN e o MERCOSUL, tiveram uma história diferente, mas se encontram hoje em situações semelhantes. Os problemas comerciais persistem e os governos parecem aceitar que muitos desses problemas não se resolvem no futuro imediato. No entanto, esses blocos persistem cada vez mais como foros políticos, e cada vez menos como blocos de integração econômica. O fato é que quase todos os acordos de integração regional formados na América Latina enfrentam problemas sérios derivados do não-cumprimento de seus objetivos principais. 
Não faltam planos bonitos e projetos ambiciosos para reinventar e redesenhar a integração regional na América Latina, tendo em vista a necessidade de uma agenda renovada de desenvolvimento, que estabelece um padrão includente e participativo de crescimento econômico sustentável, que cria empregos e valoriza a riqueza ambiental e cultural da região.

Entre esses novos projetos de integração e cooperação regional se destacam por um lado a Iniciativa para a Integração da Infra-estrutura Regional Sul Americana (IIRSA), que é à primeira vista somente um projeto de cooperação técnica, e por outro lado dois projetos políticos, o projeto da União de Nações Sul-americanas (UNASUL) e o projeto da "Alternativa Bolivariana para los pueblos de nuestra América" (ALBA).

\subsection{Projeto 1: Iniciativa para a Integração da Infra-estrutura Regional Sul Americana (IIRSA)}

Lançada em agosto de 2000, a Iniciativa para a Integração da Infraestrutura Regional Sul Americana (IIRSA) busca impulsionar a integração e a modernização da infra-estrutura física na base de um conceito regional do espaço sul-americano. $\mathrm{Na}$ linguagem oficial, a IIRSA sustenta-se em dois âmbitos de ações fundamentais. Em primeiro lugar, o ordenamento espacial do território se realiza reconhecendo a realidade geopolítica e geoeconômica do subcontinente, definindo eixos sinérgicos de integração e do desenvolvimento que vão além das necessidades de caráter físico. Esses eixos têm um conteúdo integral, buscando o desenvolvimento dos recursos humanos como fator fundamental na construção do futuro da região. Os corredores concentradores de fluxos de comércio e de investimentos atuais e potenciais foram desenhados em função dos negócios e de cadeias produtivas com grandes economias de escala para o consumo interno da região ou para a exportação ao mercado mundial. A infra-estrutura de energia de transporte e telecomunicações se desenvolve a partir desta concepção.

Em segundo lugar, o esforço da iniciativa busca a convergência de normas e mecanismos institucionais, removendo barreiras de ordem regulatória, legal, operativa e institucional que limitam o uso eficiente da infra-estrutura. Alem disso, existem barreiras que obstaculizam 
investimentos em nova infra-estrutura. É preciso remover todos aqueles obstáculos para permitir o livre comercio de bens e serviços dentro da região. Estas atividades, chamadas Processos Setoriais de Integração, buscam implementar instituições independentes de pressões políticas, tanto por lado dos governos como por lado de atores afetados. Com tais Processos Setoriais de Integração pretende-se estabelecer regras claras e estáveis que logrem a transparência nas decisões para evitar qualquer discriminação entre os distintos atores. Por mais surpreendente que seja, no projeto IIRSA pretende-se buscar, em etapas posteriores, a criação de instituições supranacionais com o objetivo de aumentar ainda mais as eficiências setoriais para aumentar a competitividade regional.

O objetivo prioritário da IIRSA é então a integração física dos doze países da América do Sul, através da modernização da infraestrutura, bem como ações setoriais para estimular a integração e o desenvolvimento de sub-regiões isoladas. A IIRSA propõe recortar o continente sul-americano em dez faixas prioritárias para investimentos em infra-estrutura de transporte, energia e telecomunicações, tendo em vista o potencial exportador de cada uma delas. Os eixos de integração e desenvolvimento são territórios transfronteiriços, nos quais investimentos na infra-estrutura ajudam a criar novas oportunidades de desenvolvimento. Os beneficiários diretos de um melhoramento nos setores energéticos, de transportes e de comunicação são os grandes grupos econômicos nacionais e internacionais, pois esses investimentos servem para baixar os custos e para aumentar a escala de produção. Dos dez eixos de integração e desenvolvimento, identificado consensualmente, cinco incluem o espaço andino (veja quadro 3 ). 


\section{Quadro 3: Os eixos de integração no espaço andino}

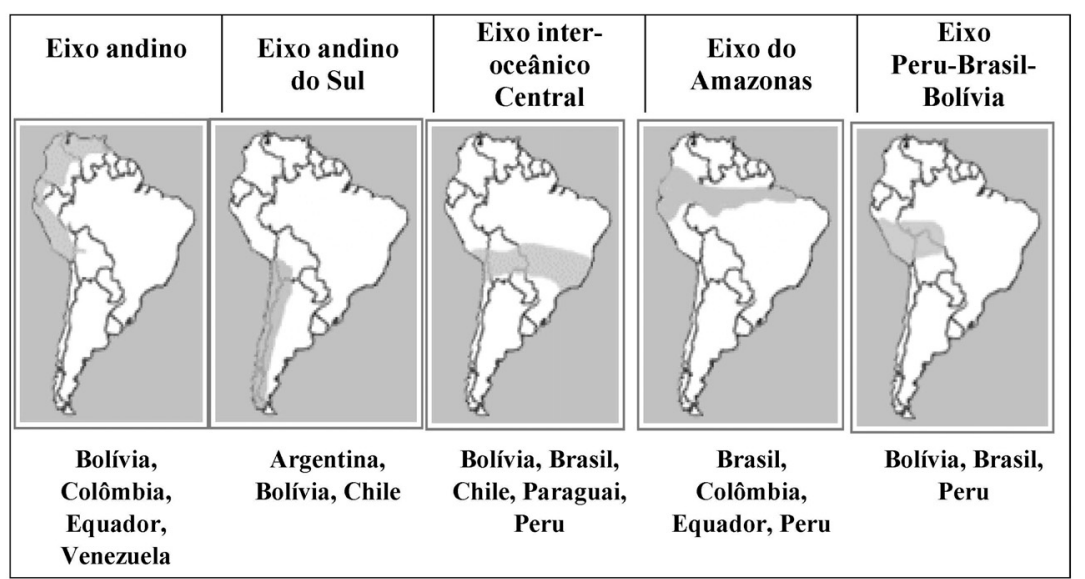

Fonte: <www.iirsa.org> (28.03.2009).

A IIRSA é, sobretudo um projeto de cooperação técnica, mas é também um projeto de alto conteúdo político, orientado a criar uma sólida base que pode sustentar um processo de integração regional para alcançar uma inserção competitiva, eficiente e eqüitativa da região no contexto da globalização. Esta iniciativa justifica-se pela necessidade de uma agenda renovada de desenvolvimento, que restabelece um padrão de crescimento sustentável, participador e não excludente, criador de empregos, que valorize a riqueza ambiental bem como a riqueza cultural da América do Sul.

\subsection{Projeto 2: Comunidade Sul-americana de Nações (CSN)/União das Nações Sul-Americanas (UNASUL)}

O projeto de uma Comunidade Sul-Americana das Nações (CSN) foi lançado pelo governo brasileiro. Conformou-se com a decisão dos doze Chefes de Estado reunidos na III Cimeira Presidencial Sul-Americana, no dia 8 de dezembro de 2004.

Segundo a Declaração de Cuzco sobre a Comunidade Sul-Americana das Nações, a CSN se conforma tendo em conta a história compartida e solidária das nações sul-americanas, que desde as gestas da independência hão enfrentado desafios internos e externos comuns. Com a formação da CSN pretende-se demonstrar que os países da 
América do Sul possuem potencialidades até agora não aproveitadas tanto para utilizar melhor suas aptidões regionais como para fortalecer as capacidades de negociações e projeções internacionais.

No entanto, por lado da CSN houve muitos anúncios de ações comuns e acordos ambiciosos, más até agora poucos resultados concretos. Um dos resultados concretos foi a modificação, em 2007, do nome do projeto. Denomina-se agora, por pedido vigoroso do presidente Hugo Chávez, União de Nações Sul-americanas (UNASUL). Outros resultados obtidos no decorrer do tempo foram a criação de um conselho energético regional e de uma secretaria permanente com sede em Quito/Equador. Mas o primeiro Secretário General da UNASUL, Rodrigo Borja, ex presidente de Equador, que ocupava o cargo desde Abril de 2007, renunciou um ano mais tarde por discrepâncias com a maioria dos doze presidentes do bloco. $\mathrm{Na}$ opinião do mandatário, os dois blocos regionais, a CAN e o Mercado Comum do Sul (Mercosul), se "acercam ao esgotamento" e por isso seria o momento de englobálos na UNASUL. Questionava-se também a criação do Conselho da UNASUL como órgão executivo de doze membros, um por cada país, que deixou a Secretaria General com pouca competência. Devido à crise temporária entre Colômbia e Equador/Venezuela no início do ano 2008, a decisão sobre a ata constitutiva da UNASUL foi adiada até maio de 2008, para a Cimeira Presidencial Extraordinária realizada em Brasília. Naquela ocasião, o presidente Luiz Inácio Lula da Silva, do Brasil, ao saudar a criação da UNASUL, afirmou que o novo organismo está realizando um sonho maior que o de Simon Bolívar quando bradou a criação da Grã Colômbia, pois "está acontecendo uma coisa extraordinária", a criação da "grande nação sul-americana". ${ }^{1}$

Apesar da toda a poesia e retórica integracionista, é óbvia a postura de alguns países-membros, e entre eles o Brasil, de restringir a UNASUL a um acordo intergovernamental e não supranacional, sem avançar para uma integração mais profunda. De fato, o poder de decisão foi transferido ao Conselho da UNASUL, que se reúne em cada dois meses. Com essa estrutura a UNASUL foi convertida num mero foro político, dos quais já existem demasiadamente muitos na América Latina. Ou em outras palavras: o projeto da UNASUL deixou de garantir a construção de um novo modelo de integração regional e tam-

$1<$ www.integracionsur.com/sudamerica/UNASULLulaBolivar.htm> (28.03.2009). 
pouco aproveitou efetivamente as experiências positivas de mecanismos de integração regional já existentes.

\subsection{Projeto 3: Alternativa Bolivariana para os povos da nossa América (ALBA)}

Lançada em 2004, por Cuba e Venezuela, a ALBA é entendida pelos seus protagonistas como uma proposta de repensar os acordos de integração em função de alcançar um desenvolvimento endógeno nacional e regional que erradique a pobreza, corrige as desigualdades sociais e assegure uma crescente qualidade de vida para os povos da América Latina e do Caribe. ${ }^{2}$ Partindo da suposição de que hoje mais do que nunca haja que relançar a unidade latino-americana e caribenha, a proposta da ALBA quer despertar a consciência que se expressa na emergência de uma nova liderança política, econômica, social e militar na América Latina e no Caribe. A ALBA se entende como uma proposta de integração diferente para a América Latina e o Caribe. O conceito básico prevê a criação de "vantagens cooperativas" entre as nações que permitam compensar as assimetrias existentes. Baseia-se na cooperação de fundos compensatórios para corrigir as disparidades que colocam em desvantagem os países fracos frente às primeiras potências.

O projeto da ALBA, da co-autoria de Fidel Castro e Hugo Chávez, foi tornado público como proposta alternativa baseada na solidariedade. Trata-se da pretensão de ajudar os países mais débeis do subcontinente a superar as desvantagens que os separam dos países mais poderosos da América Latina. Corrigir estas assimetrias não seria possível sem a solidariedade entre os povos e os seus governos. É somente com essa solidariedade que uma área de livre comércio poderá ser uma oportunidade para todos, uma aliança ganhar-ganhar. É evidente que o projeto da ALBA foi desenhado inicialmente como contra-ataque ao projeto dos Estados Unidos de formar uma Área de Livre Comércio das Américas (ALCA). No entanto, a ALCA foi enterrada clandestinamente.

2 Acuerdo entre el presidente de la república bolivariana de Venezuela y el presidente del consejo de Estado de Cuba, para la aplicación de la alternativa bolivariana para las Américas, 14.12.2004. <www.alternativabolivariana.org/ modules.php?name $=$ News $\&$ file $=$ article $\&$ sid $=81>(28.03 .2009)$. 
Passo em passo, o eixo Cuba-Venezuela foi alargado e a ALBA ganhou força com a ascensão ao poder dos chamados governos de esquerda neopopulista. A Bolívia incorporou-se na ALBA em 2006, depois da vitória do Evo Morales nas eleições presidenciais. ${ }^{3}$ A Nicarágua sob o comando de Daniel Ortega entrou em 2007, bem como a Dominica. ${ }^{4}$ Eleito presidente da Republica de Honduras, José Manuel Zelay Rosales decidiu, em 2008, ajuntar seu país à ALBA. ${ }^{5}$ E tem outros aspirantes. Entre eles o Equador, cujo presidente Rafael Correa continua analisando uma possível adesão à ALBA; também o Haiti que já firmou, em Abril de 2008, um convênio marco de cooperação com a ALBA. ${ }^{6}$ e talvez El Salvador, depois da vitória da Frente Farabundo Martí para a Liberação Nacional (FMLN) e do seu candidato Mauricio Funes nas eleições presidenciais em Março de 2009.

A ALBA, sob a tutela do carismático Hugo Chávez e seus petrodólares, tem lançado muitos planos bonitos para aumentar a atratividade político-econômica do projeto, como por exemplo, o lançamento do Sucre como moeda única da ALBA, a criação do banco da ALBA, bem como um Tratado de Comercio dos Povos (ALBA-TLC). Mas muitos dos planos ficam no papel, enquanto a situação econômica da Venezuela está se piorando com a queda do preço de petróleo no mercado mundial e com as intervenções discricionárias do Chávez na economia do país, desrespeitando leis e regras.

Em termos meramente econômicos, é difícil entender a decisão do presidente da Venezuela de despedir-se da CAN e formar um eixo

3 Contribución y suscripción de la república de Bolivia a la declaración conjunta firmada en la Habana, el 14 de diciembre del 2004, entre los presidentes del consejo de estado de la república de Cuba y de la república bolivariana de Venezuela, 29.04.2006. <www.alternativabolivariana.org/modules.php?name= Content\&pa $=$ showpage\&pid $=514>(28.03 .2009)$.

4 Acuerdo para la cooperación económica y social entre el gobierno de la mancomunidad de Dominica y el gobierno de la república bolivariana de Venezuela, 29.02.2007. $<w w w$.alternativabolivariana.org/modules.php?name $=$ Content $\& p a=$ showpage \&pid=1966> (28.03.2009).

5 Declaración de adhesión de la república de Honduras a la alternativa bolivariana para los pueblos de nuestra América (ALBA), 16.09.2008.

$<$ www.alternativabolivariana.org/modules.php?name $=$ Content\&pa $=$ showpage\&p $\mathrm{id}=1969>(28.03 .2009)$.

6 V Cumbre del ALBA - Convenio marco de cooperación ALBA-Haití, 29.04. 2007. $<$ www.alternativabolivariana.org/modules.php?name $=$ News\&file $=$ article $\&$ sid=1806> (28.03.2009). 
com Bolívia e Cuba, pois não se pode comparar a importância da aliança bolivariana com a CAN. Mesmo a CAN enfraquecida possui um potencial econômico muito maior que a do eixo bolivariano que Hugo Chávez acabou de formar. Não é fácil encontrar uma racionalidade econômica para trocar muito por tão pouco. Apesar disso, a Alternativa Bolivariana de Hugo Chávez e companheiros não pode servir como nova arquitetura para a integração regional na América Latina, pois o nacionalismo exagerado é o antagonismo da integração regional que exige, no mínimo, livre comércio e algumas perdas de soberania. Ou em outras palavras: a ALBA é incompatível com a idéia de uma verdadeira integração. Construir um bloco de integração econômica e política como "Alternativa Bolivariana para a nossa América" exige obviamente muito mais do que alguns planos bonitos. A integração sul-americana não se realiza com parceiros instáveis, compartilhando seu destino com sócios duvidosos e inconfidentes.

Visto de fora, a maioria dos novos projetos e modelos de integração na América Latina contém uma alta dose de utopia - herança do pensamento integracionista na América Latina desde os tempos de Simón Bolívar. Os novos projetos abrangem distintas concepções ideológicas que refletem a diversidade política da realidade atual. Uma nova linha de Tordesilhas está separando a América Latina. Em termos de política econômica, é a linha ideológica entre o "bloco bolivariano" e um "bloco pacífico" (veja quadro 4 e 5).

No "bloco bolivariano", o vago conceito de um "socialismo do século XXI" está orientando a política econômica. É um bloco de países com baixa competitividade internacional, cuja base é sobretudo a exportação de produtos primários. É um bloco sem complementaridades econômicas e com poucas sinergias, com entrelaçamentos econômicos fracos.

No "bloco pacífico", composto informalmente ao longo da costa do Oceano Pacífico pelo Chile, Peru, Colômbia, Costa Rica e México, se agrupam economias latino-americanas cuja política econômica continua buscando orientação no paradigma neoliberal e na integração no mercado mundial. Em termos de livre comércio, o bloco tem a simpatia declarada ou implícita de aliados fora da região, como o Canadá e a União Européia. 

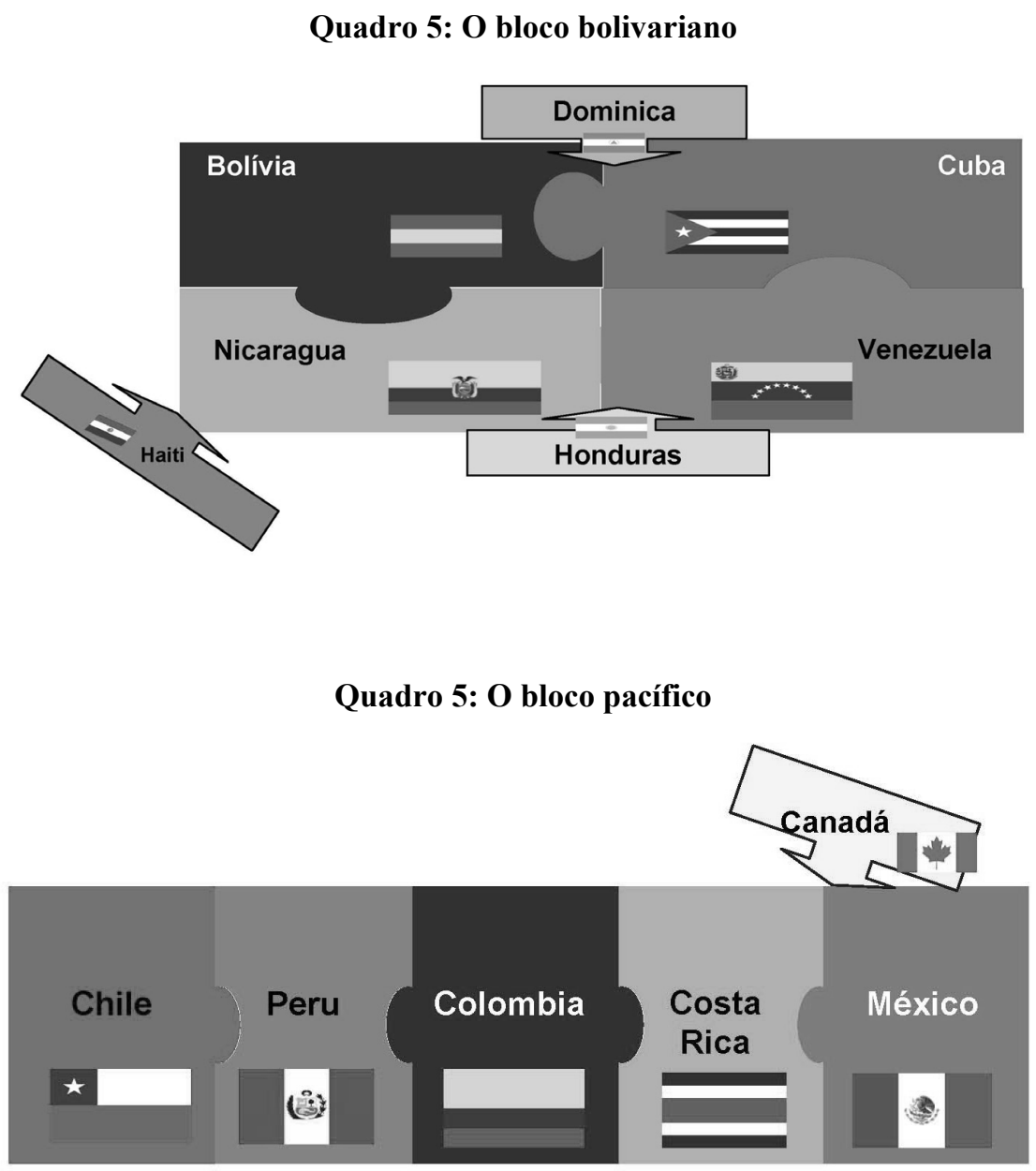

E aonde será o lugar do Brasil? Apesar da retórica de solidariedade do presidente Lula nas cimeiras latino-americanas, o Brasil anda sozinho se outros países não estão dispostos a acompanhá-lo. O Brasil age com seus setores da economia nacional que já alcançaram competitividade internacional no clube de "gansos voadores" das economias emergentes, enquanto deixa os países vizinhos formar um clube de "patos sentados", continuando discutir sobre a revolucionária alternativa bolivariana. 
Apesar das boas intenções em termos de integração regional, o subcontinente sul-americano está vivendo momentos difíceis em termos de integração regional. O melhor que se possa esperar atualmente são convênios de convivência que respeitem a soberania de cada um dos países do subcontinente. Por enquanto, a unidade latino-americana parece ser um sonho irrealizável, desde que ela foi tentada por Simón Bolívar. O fato é, que os projetos sul-americanos de formar blocos regionais integrados até agora foram limitados a um ou outro acordo comercial modesto. Uma tentativa séria de integração regional na América do Sul ainda está para ser feita. Uma integração solidária na América do Sul implica, necessariamente, perdas de soberania nacional, pois a cooperação entre nações não pode ser mais pensada como uma cooperação internacional, mas sim como transnacional. Juntos, os países sul-americanos poderiam ter boas chances de aumentar o seu poder de barganha e lidar melhor com as suas complementaridades e sinergias econômicas. Diga-se de passagem, que a América do Sul teria condições para tanto, se houvesse um convencimento da sociedade civil e da classe política das vantagens concretas de uma integração regional efetiva, ao estilo da União Européia. É bem lembrar, neste contexto, que o processo da integração econômica e política da Europa foi um processo lento e gradual, culminando na formação da União Monetária Européia somente 40 anos depois do Tratado de Roma. Comparada a essa experiência histórica, a América do Sul tem ainda muito tempo para unir-se. Mas por enquanto, visto de fora, a integração econômica da América do Sul parece ser utópica.

Aprofundar e alargar as alianças de integração na América do Sul só será possível se as percepções e expectativas dos Estados membros chegarem a coincidir, se uma agenda política comum puder ser estabelecida, e se for alcançado um nível mais alto de institucionalização da política de integração. Sem uma convergência macroeconômica, sobretudo em direção à estabilidade monetária e compatibilidade cambial, é difícil imaginar avanços nos processos de integração regional na América do Sul. 


\section{Bibliografia}

Bodemer, Klaus/Gratius, Susanne (2003): Lateinamerika im internationalen System zwischen Regionalismus und Globalisierung. Wiesbaden: VS Verlag.

CEPAL (Comisión Económica para America Latina y el Caribe) (2007): Panorama de la inserción internacional de América Latina y el Caribe 2006. Tendencias 2007. Santiago de Chile: CEPAL.

Di Filippo, Armando (1998): Integración regional latinoamericana, globalización y comercio sur-sur. Santiago de Chile: CEPAL.

Durán Lima, José E./Masi, Fernando (2007): Diagnóstico de las asimetrías en los procesos de integración de América del Sur. Santiago de Chile: CEPAL.

IDB (Inter-American Development Bank) (2002): Beyond Borders: the New Regionalism in Latin America. Economic and Social Progress in Latin America 2002 Report. Washington, D.C.: IDB.

Inter-American Development Bank (2007): Intergration and Trade Sectors Briefs. Latin America Annual Trade Estimates for 2007. Washington, D.C.: IDB.

Nunnenkamp, Peter (2001): "Ist diesmal alles anders? Die neue Welle regionaler Integration in Lateinamerika aus europäischer Perspektive". Em: Bodemer, Klaus et al. (orgs.): Lateinamerika Jahrbuch 2001. Frankfurt am Main: Vervuert, pp. 929.

Rosales, Osvaldo (2006): "Crisis de la integración y convergencia de acuerdos comerciales". Em: Notas dela CEPAL, 46. Santiago de Chile: CEPAL, pp. 4-5.

Sangmeister, Hartmut (2004): "O futuro da integração latinoamericana: lições do passado e experiências da 'velha' Europa”. Em: Steckbauer, Sonja M./Maihold, Günther (orgs.): Literatura, historia, política: articulando las relaciones entre Europa y América Latina. Frankfurt am Main: Vervuert, pp. 225-237.

Sangmeister, Hartmut/Fuentes, Raquel (2002): “ALCA vs. ALCSA? Perspectivas de la integración latinoamericana”. Em: $D+C$ Desarrollo y Cooperación, 1, pp. 2732.

Serbin, Andrés (2007): "Entre Unasur y ALBA: ¿otra integración (ciudadana) es posible?". Em: Mesa, Manuela (org.): Paz y conflictos en el siglo XXI: tendencias globales. Anuario 2007-2008. Barcelona: Icaria Editorial, pp. 183-207. 
